\title{
Erratum to: Interannual variations of the dominant modes of East Asian winter monsoon and possible links to Arctic sea ice
}

\author{
Chenghu Sun ${ }^{1}$ - Song Yang ${ }^{2,3} \cdot$ Weijing $\mathrm{Li}^{1} \cdot$ Ruonan Zhang ${ }^{1,4} \cdot$ Renguang $\mathrm{Wu}^{5}$
}

Published online: 1 August 2016

(C) Springer-Verlag Berlin Heidelberg 2016

\section{Erratum to: Clim Dyn (2016) 47:481-496 DOI 10.1007/s00382-015-2851-3}

We would like to draw attention to the following editorial errors in section 5 of further discussion:

1. To explore the SAT and Arctic sea ice associated with DJF AO, We calculate the correlation between the AO index with winter SAT and Arctic sea ice. In the sentence, the capital form of We should be lowercase of we.

2. It is found that cold anomalies occur in the mid-higher latitudes of the Eurasian continent when AO is negative, resembling the distribution of cold anomalies over Eurasia shown in Fig. 3c. In the sentence, the Fig. 3c should be corrected as Fig. 2c.

The online version of the original article can be found under doi:10.1007/s00382-015-2851-3.

\section{Song Yang}

yangsong3@mail.sysu.du.cn

1 National Climate Center, China Meteorological Administration, Beijing, China

2 Department of Atmospheric Sciences, Sun Yat-sen University, 135 West Xingang Road, Guangzhou 510275, China

3 Institute of Earth Climate and Environment System, Sun Yat-sen University, Guangzhou, China

4 Chinese Academy of Meteorological Sciences, China Meteorological Administration, Beijing, China

5 Center for Monsoon System Research, Institute of Atmospheric Physics, CAS, Beijing, China
3. In this paper, we suggest that the Arctic sea ice loss influences the northern mode of EAWM through both dynamic and thermodynamic process (e.g., the surface radiative cooling due to increased snow cover), and that the role of snow cover anomalies shall not be ignored as shown in the CMA3 model simulation results. In the sentence, the CMA3 should be corrected as CAM3. 